\title{
Thin-film formation of Si clathrates on Si wafers
}

Fumitaka Ohashi, ${ }^{1}$ Yoshiki Iwai, ${ }^{1}$ Akihiro Noguchi, ${ }^{1}$ Tomoya Sugiyama, ${ }^{1}$ Masashi Hattori, ${ }^{1}$ Takuya Ogura, ${ }^{3}$ Roto Himeno, ${ }^{1}$ Tetsuji Kume, ${ }^{2}$ Takayuki Ban, ${ }^{3}$ Shuichi Nonomura ${ }^{1}$

${ }^{1}$ Environmental and Renewal Energy Systems Division, Graduate School of Engineering, Gifu University, 1-1 Yanagido, Gifu 501-1193, Japan

${ }^{2}$ Department of Electrical, Electronic and Computer Engineering, Faculty of Engineering, Gifu University, 1-1 Yanagido, Gifu 501-1193, Japan

${ }^{3}$ Department of Chemistry and Biomolecular Science, Faculty of Engineering, Gifu University, 1-1 Yanagido, Gifu 501-1193, Japan

Email: f_ohashi@gifu-u.ac.jp

\begin{abstract}
In this study, we prepared $\mathrm{Si}$ clathrate films $\left(\mathrm{Na}_{8} \mathrm{Si}_{46}\right.$ and $\left.\mathrm{Na}_{\mathrm{x}} \mathrm{Si}_{136}\right)$ using a single-crystalline Si substrate. Highly oriented film growth of Zintl-phase sodium silicide, which is a precursor of $\mathrm{Si}$ clathrate, was achieved by exposing $\mathrm{Na}$ vapor to $\mathrm{Si}$ substrates under an Ar atmosphere. Subsequent heat treatment of the NaSi film at $400{ }^{\circ} \mathrm{C}(3 \mathrm{~h})$ under vacuum $\left(<10^{-2} \mathrm{~Pa}\right)$ resulted in a film of $\mathrm{Si}$ clathrates having a thickness of several micrometers. Furthermore, this technique enabled the selective growth of $\mathrm{Na}_{8} \mathrm{Si}_{46}$ and $\mathrm{Na}_{\mathrm{x}} \mathrm{Si}_{136}$ using the appropriate crystalline orientation of $\mathrm{Si}$ substrates.
\end{abstract}

Keywords: Silicon clathrate, Sodium silicide, Thermal decomposition, Thin film

pg. 1 


\section{Introduction}

Group IV clathrates are materials that are composed of polyhedral cages encapsulating alkali metals as guest atoms such as $\mathrm{A} @ \mathrm{E}_{20}, \mathrm{~A} @ \mathrm{E}_{24}$, and $\mathrm{A} @ \mathrm{E}_{28}(\mathrm{~A}=$ alkali metal, $\mathrm{E}=\mathrm{Si}$ or $\mathrm{Ge}$ ) $[1,2]$. The crystalline structures of the clathrates are classified by combinations of cage structures into type $\mathrm{I}\left(\mathrm{A}_{8} \mathrm{E}_{46}: \mathrm{A} @ \mathrm{E}_{20} \times 2+\mathrm{A} @ \mathrm{E}_{24} \times 6\right)$, type II $\left(\mathrm{A}_{24} \mathrm{E}_{136}: \mathrm{A} @ \mathrm{E}_{20} \times 16+\mathrm{A} @ \mathrm{E}_{24} \times 8\right)$, and other forms [2]. Type I and type II are both cubic structures with space groups of Pm-3n and Fd-3 m, respectively.

Clathrates that are fully occupied by guest atoms in those cages induce various interesting properties owing to guest-host interaction [3-6], such as superconductivity [7] and low thermal conductivity [8-11]. The latter property is important for applications in thermoelectric devices. On the other hand, clathrates without guest atoms, known as guest-free clathrates, exhibit semiconductor properties [12-19]. For type II, guest-free $\mathrm{Si}_{136}$ and $\mathrm{Ge}_{136}$ clathrates have been experimentally obtained, and the reported band-gap energy of $\mathrm{Si}_{136}$ is in the visible region $(\sim 1.8 \mathrm{eV})$ [13]. In addition, semiconducting properties of clathrate materials are also investigated using $\mathrm{Na}_{x} \mathrm{Si}_{136}$ with a reduction in concentrations $x$ of Na guest atoms $[17,18]$. Such a visible band gap of Si-related materials has attracted the interest of many material scientists, especially those researching band-gap engineering for solar cells [15]. Although clathrate materials possess various potentially beneficial properties, their practical application remains problematic because of the difficulty in realizing thin-film 
formation.

To the best of our knowledge, there are only two reports concerning the films of clathrate materials. One study involves a Ge-based ternary clathrate with a type I structure $\left(\mathrm{Ba}_{8} \mathrm{Ga}_{16} \mathrm{Ge}_{30}\right)$ [20]. This clathrate can be categorized into a Zintl phase because electronic charges are balanced between guest and host cages (e.g., $\left.\left(\mathrm{Ba}^{2+}\right)_{8}\left(\mathrm{Ga}^{1-}\right)_{16} \mathrm{Ge}_{30}\right)[8,20,21]$. It is commonly known that Zintl-phase clathrates are prepared in one step, i.e., by melting the respective elements [20]. Thus, the film can be formed rather easily by annealing the mixture of the elements deposited on a substrate. The other study focuses on a Si-based binary clathrate with the type I structure $\mathrm{Na}_{8} \mathrm{Si}_{46}$ [22]. In contrast with the ternary clathrate, binary clathrates can be synthesized using a NaSi precursor. According to Narita et al. [22], NaSi precursor films were prepared by a reaction of a Si substrate with Na vapor, and one XRD peak corresponding to $\mathrm{Na}_{8} \mathrm{Si}_{46}$ appeared after the thermal decomposition of the $\mathrm{NaSi}$ film. However, no attempts were made to prepare thin films of $\mathrm{Na}_{x} \mathrm{Si}_{136}$. Actually, apart from our study, binary clathrates have been synthesized as either powders or very small crystallines.

In this study, we found that the use of $\mathrm{Si}$ wafers as the single-crystalline $\mathrm{Si}$ source and substrate resulted in the film formation of binary $\mathrm{Si}$ clathrates $\mathrm{Na}_{8} \mathrm{Si}_{46}$ and $\mathrm{Na}_{x} \mathrm{Si}_{136}$. First, we confirmed preparations of the Zintl-phase NaSi precursor as a film formed on the $\mathrm{Si}$ substrate by the surface reactions with $\mathrm{Na}$ vapor. Subsequent annealing under vacuum transformed the NaSi films into Si clathrate films. In addition, the selective growth of type I 
$\left(\mathrm{Na}_{8} \mathrm{Si}_{46}\right)$ and type II $\left(\mathrm{Na}_{\mathrm{x}} \mathrm{Si}_{136}\right) \mathrm{Si}$ clathrates was achieved by choosing the crystalline orientation of Si substrates.

\section{Experimental method}

The films of Na-doped Si clathrates were prepared using single-crystalline $\mathrm{Si}$ substrates as starting materials. The procedure was basically the same as that for powder $\mathrm{Si}$ clathrates [24-26]: the annealing of Si substrates with elemental $\mathrm{Na}$ under an Ar atmosphere is followed by annealing under vacuum. Si substrates with (100) or (111) surfaces (Miyoshi, Japan: B doped and undoped, $10^{-2}$ to $10^{3} \Omega \cdot \mathrm{cm}, 20 \mathrm{~mm} \times 8 \mathrm{~mm} \times 0.5 \mathrm{~mm}$ mirror polished on one side) were washed by HF ( $5 \%)$ and deionized water. The substrates were horizontally placed $10 \mathrm{~mm}$ above the sodium slice (Sigma-Aldrich, Japan, 99\%) in a Ta crucible. The Ta crucible was placed in a sealed stainless steel container under an Ar atmosphere (>99.999\%) and was heated at $500-600{ }^{\circ} \mathrm{C}$ for $24-96 \mathrm{~h}$ using a muffle furnace. The Si substrates, which reacted with $\mathrm{Na}$ vapor to form $\mathrm{NaSi}$ on their surface, were taken out of the container under the Ar atmosphere and transferred into a vacuum furnace consisting of a quartz tube $(80 \mathrm{~mm}$ in diameter and $1200 \mathrm{~mm}$ in length). The vacuum furnace was pumped down using a rotary pump and a turbo molecular pump until the pressure decreased below $10^{-2} \mathrm{~Pa}$. Then, the substrates were annealed at $400{ }^{\circ} \mathrm{C}$ for $3 \mathrm{~h}$ under vacuum for the thermal decomposition of $\mathrm{NaSi}$ films. For comparison, a powder $\mathrm{Si}$ clathrate was prepared from $\mathrm{Na}$ lumps 
(Sigma-Aldrich, Japan, 99\%) and diamond-structured Si powder (Niraco, Japan, 99.999\%) with thermal annealing under an $\mathrm{Ar}$ atmosphere at $650{ }^{\circ} \mathrm{C}$ for $48 \mathrm{~h}$ and subsequent annealing under vacuum at $400{ }^{\circ} \mathrm{C}$ for $3 \mathrm{~h}$. The prepared samples were characterized by $\mathrm{X}$-ray diffraction (XRD: Rigaku RINT Ultima IV, monochromatic $\mathrm{Cu} \mathrm{K \alpha}$, concentration method) and scanning electron microscopy (SEM: Hitachi-4300).

\section{Results}

The results of the fabrication of $\mathrm{Si}$ clathrates on a $\mathrm{Si}(100)$ substrate are shown in Figs. 1 (a) and (b). Initially, the $\mathrm{Si}(100)$ substrate reacted with $\mathrm{Na}$ vapor at $500{ }^{\circ} \mathrm{C}$ under an Ar atmosphere for $24 \mathrm{~h}$. The resultant sample clearly showed XRD peaks of Zintl-phase NaSi, as indicated at the bottom of Fig. 1 (a). However, the number of observed peaks was much smaller than that in the powder $[27,28]$. Only specific diffraction peaks were observed, demonstrating that the synthesized NaSi film is highly orientated on the $\mathrm{Si}(100)$ substrate. The synthesized NaSi was then transformed into Si clathrates by second annealing at $400{ }^{\circ} \mathrm{C}$ for $3 \mathrm{~h}$ under vacuum. The XRD pattern measured after the second annealing is shown at the top of Fig. 1 (a). From the diffraction pattern, we recognized that the type I Si clathrate $\mathrm{Na}_{8} \mathrm{Si}_{46}$ had been formed. Because the relative intensities of the diffraction peaks are the same as those of the powder, $\mathrm{Na}_{8} \mathrm{Si}_{46}$ is found to be polycrystalline with random orientation. The lattice constant of $\mathrm{Na}_{8} \mathrm{Si}_{46}$ was estimated as $d=10.19 \AA$, which is similar to the value 
obtained in a previous study [23]. The SEM image of the final product is shown in Fig. 1 (b). An approximately $15-\mu \mathrm{m}$-thick $\mathrm{Si}$ clathrate was successfully synthesized on top of the $\mathrm{Si}(100)$ substrate. It should be noted that the synthesized clathrate was not of type II, but of type I, although the annealing condition of $400{ }^{\circ} \mathrm{C}$ under a high vacuum of $10^{-4} \mathrm{~Pa}$ was adopted in order to preferentially synthesize type II. This will be discussed later.

To gain an insight into the generation of the Si clathrate on the $\mathrm{Si}(100)$ substrate, we changed the condition required to prepare NaSi: the Ar annealing temperature was elevated from 500 to $550{ }^{\circ} \mathrm{C}$, while the other parameters remained the same. The XRD patterns of the NaSi precursor and the resultant sample are shown in Fig. 2. We observed the same specific NaSi peaks as those in the earlier case (Fig. 1), indicating that the NaSi film with the same crystalline orientation is formed. However, the resultant product was quite different in that the type II $\mathrm{Na}_{x} \mathrm{Si}_{136}$ clathrate with a lattice constant of $14.64 \AA$ was synthesized as a major phase, as seen in Fig. 1. Despite using the same precursor and the same condition during subsequent annealing, the different types of clathrates (type I or type II clathrates) were eventually produced. The reason for this will be discussed later.

To explore the influence of the substrate, we used the Si substrate with the (111) surface instead of that with the (100) surface. Because Ar annealing at $500{ }^{\circ} \mathrm{C}$ for $24 \mathrm{~h}$ did not generate $\mathrm{NaSi}$ on the $\mathrm{Si}(111)$ surface, the annealing temperature was elevated to $580{ }^{\circ} \mathrm{C}$, but the other parameters were not changed. We confirmed the synthesis of $\mathrm{NaSi}$ on $\mathrm{Si}(111)$, as 
indicated in the XRD pattern at the bottom of Fig. 3 (a). Similar to the case of $\mathrm{Si}(100)$, a highly orientated NaSi film was found to have grown because only a few XRD peaks were observed. However, the crystalline orientation was different from that on $\operatorname{Si}(100)$ substrates, because the number and relative intensities of the observed XRD peaks were different. To fabricate the Si clathrate, the NaSi film then underwent the second annealing step at $400{ }^{\circ} \mathrm{C}$ for $3 \mathrm{~h}$ under vacuum. The measured XRD pattern is shown at the top of Fig. 3 (a). Almost all of the peaks were attributed to those from $\mathrm{Na}_{\mathrm{x}} \mathrm{Si}_{136}$ (type II) with a lattice constant $a=14.62$ $\AA$. The lattice constant of $\mathrm{Na}_{\mathrm{x}} \mathrm{Si}_{13}$ grown on $\mathrm{Si}$ substrates was almost the same as or slightly greater than that reported for a guest-free type II Si clathrate $(a=14.62601(9))$ [13]. $\mathrm{Na}_{\mathrm{x}} \mathrm{Si}_{136}$ grown on the $\mathrm{Si}(111)$ substrate was presumed to be polycrystalline because the relative intensities of diffraction peaks were the same as those of the powder. The peaks located at $2 \theta$ $=14.2,28.4$, and $58.9^{\circ}$, denoted by an open triangle, originated from the Si(111) substrate. The cross-sectional SEM image of this product is shown in Fig. 3 (b). A 2- $\mu$ m-thick Si clathrate film was grown on the $\operatorname{Si}(111)$ substrate. The thickness was lesser than that on the $\mathrm{Si}(100)$ surface despite the use of higher annealing temperatures to prepare NaSi. This is because the reactivity of the $\mathrm{Si}(111)$ surface with $\mathrm{Na}$ vapor was lower than that of the $\mathrm{Si}(100)$ surface. To the best of our knowledge, this is the first report of the synthesis of $\mathrm{Na}_{\mathrm{x}} \mathrm{Si}_{136}$ films. Despite having the same crystallinity of the NaSi precursor, as indicated in Figs. 1 and 2, the final product ( $\mathrm{Si}$ clathrates) had a different type of structure. NaSi prepared by 
annealing at $550{ }^{\circ} \mathrm{C}$ led to type II $\left(\mathrm{Na}_{x} \mathrm{Si}_{136}\right)$, whereas the one prepared by annealing at $500{ }^{\circ} \mathrm{C}$ produced type $\mathrm{I}\left(\mathrm{Na}_{8} \mathrm{Si}_{46}\right)$. Because the higher (or lower) annealing temperature is expected to form thicker (or thinner) $\mathrm{NaSi}$, the thickness of NaSi will most likely affect the final products. In general, thinner films are believed to be more strongly influenced by the substrate. To investigate the influence of precursor film thickness, we prepared both thin and thick clathrate films by varying annealing conditions (temperature and duration). The XRD patterns and cross-sectional SEM images are shown in Fig. 4. Note that the 1st and 3rd XRD patterns and SEM images from the top were the same as those shown in Figs. 1 and 3, respectively. For comparison, the XRD pattern of the powder sample was also shown in the figure. The annealing condition under vacuum $\left(400{ }^{\circ} \mathrm{C}, 3 \mathrm{~h}\right.$, and $\left.<10^{-2} \mathrm{~Pa}\right)$ for the powder sample was the same as that for the film samples. As shown in Fig. 4, the powdered sample contained type II $\left(\mathrm{Na}_{\mathrm{x}} \mathrm{Si}_{136}\right)$ as the main phase and type I $\left(\mathrm{Na}_{8} \mathrm{Si}_{46}\right)$ as the minor phase because the present annealing condition was adopted to preferentially synthesize type II $[25,26]$. For the thicker samples on $\mathrm{Si}(111)$ and $\mathrm{Si}(100)$ (the 2 nd and 4th patterns and images, respectively), a small number of type I clathrates were found in addition to the main phase of type II, which is basically the same as the case of the powder.

As described earlier, in the case of the thinner sample prepared on $\operatorname{Si}(100)$ substrates, XRD peaks were observed from the type I clathrate only (the 1st pattern in Fig. 4). For the thinner sample on the $\mathrm{Si}(111)$ substrate (the 3rd pattern in Fig. 4), the strongest line of type I was not 
clearly distinguished from noise signals. Thus, the thinner sample on the $\mathrm{Si}(111)$ substrate may consist of the type II clathrate only. Consequently, type I $\left(\mathrm{Na}_{8} \mathrm{Si}_{46}\right)$ and II $\left(\mathrm{Na}_{x} \mathrm{Si}_{136}\right)$ are preferentially grown on $\mathrm{Si}(100)$ and $\mathrm{Si}(111)$ substrates, respectively, because of the influence of the substrate in the case of the thinner samples.

\section{Discussion}

Synthesis for the selective growth of type I and II Si clathrates has been widely investigated. [23-25, 28-30]. The main strategy has been to control the Na partial pressure and temperature involved in the formation of Si clathrates. However, it has been difficult to obtain a single phase of the Si clathrate for the type I structure. In this study, for the thinner samples, we successfully achieved the selective growth of both types I and II by using the $\operatorname{Si}(100)$ and $\operatorname{Si}(111)$ substrates, respectively, despite the identical annealing condition under vacuum, which was adopted to preferentially synthesize type II. This means that type I and type II Na-doped Si clathrates can be selectively synthesized by the appropriate choice of the $\mathrm{Si}$ substrate and the control of the $\mathrm{Na}$ vapor pressure, which is important for practical applications.

Because the clathrate structure for the thinner sample is influenced by the $\mathrm{Si}$ substrate, we consider that the nucleation of the clathrate structure occurs at the interface between the NaSi and the Si surfaces. It is well known that the $\mathrm{Si}(111)$ and (100) planes are 
very different from each other with respect to their atomic arrangements and symmetry. The former and latter have three- and four-fold symmetries, respectively. According to Stefanoski et al. [23], who synthesized several hundred micrometer-sized single-crystalline Si clathrates, the crystalline growth plane of the type II Si clathrate is the $\{111\}$ plane [23]. On the other hand, for the type I Si clathrate, the crystalline growth plane is the $\{100\}$ plane [23]. Therefore, we may conclude that the agreement of the symmetries between the growth plane and the Si surface leads to the preferential growth of type I and II clathrates on the $\mathrm{Si}(100)$ and $\operatorname{Si}(111)$ surfaces, respectively. No epitaxial growth was observed for either the $\operatorname{Si}(100)$ or (111) surfaces, as seen in the powder-like XRD patterns (Figs. 1 and 3, respectively). This may be because the lattice mismatch between $\mathrm{Si}$ and $\mathrm{Si}$ clathrates is too large for epitaxial growth. For the thicker samples, no selective growth was observed since nucleation would occur not only at the $\mathrm{NaSi}-\mathrm{Si}$ interface but also at various other points in $\mathrm{NaSi}$ films. However, because of the limited information regarding the mechanism behind the synthesis of the binary clathrate on substrates, there is room for further discussion on these points.

\section{Conclusions}

In summary, we investigated the film formation of type I and type II Si clathrates according to the reaction of $\mathrm{Si}$ substrates with $\mathrm{Na}$ vapor. A highly orientated NaSi precursor was successfully fabricated on the Si substrates as the film was formed by exposing the $\mathrm{Si}$ 
surface to $\mathrm{Na}$ vapor under an Ar atmosphere. Si clathrate films were then obtained by the thermal decomposition of the NaSi films. In addition, the selective growth of types I and II Si clathrates was demonstrated by selecting the appropriate Si substrates. For sufficiently thin films of approximately less than or equal to $10 \mu \mathrm{m}$, a type I Si clathrate was formed on $\mathrm{Si}(100)$ substrates, whereas a type II Si clathrate was grown on $\mathrm{Si}(111)$ substrates. We considered that the selective growth of $\mathrm{Si}$ clathrates in the film is important to precisely determine their electronic and optical properties, as well as for applications involving electric devices employing clathrates.

\section{Acknowledgments}

These experiments were conducted as a part of the Advanced Low Carbon Technology Research Project and Development Program (ALCA) with financial support received by the Japan Science and Technology Agency (JST).

References

[1] S. Bobev, S. C. Sevov, J. Solid State Chem. 153 (2000) 92-106.

[2] K. A. Kovnir, A. V. Shevelkov, Russ. Chem. Rev. 73 (2004) 923-938.

[3] A. D. Ritchie, M. A. MacDonald, P. Zhang, M. A. White, M. Beekman, J. Gryko, G. S. 
Nolas, Phys. Rev. B 82 (2010) 155207.

[4] J. Gryko, P. F. McMillan, O. F. Sankey, Rhys. Rev. B 54 (1996) 3037-3039.

[5] A. A. Demkov, O. F. Sankey, K. E. Schmidt, G. B. Adams, M. O’Keeffe, Phys. Rev. B 50 (1994) 17001-17008.

[6] V. I. Smelyansky, J. S. Tse, Chem. Phys. Lett. 264 (1997) 459-465.

[7] H. Kawaji, H. Horie, S. Yamanaka, M. Ishikawa, Phys. Rev. Lett. 74 (1995) 1427-1429.

[8] G. S. Nolas, J. Sharp, J. Goldsmid, Springer, New York, 2001.

[9] G. S. Nolas, H. Gryko, G. A. Lamberton, T. M. Tritt, P. F. MacMillan, Appl. Phys. Lett. 82 (2003) 1544640.

[10] Y. Mudryk, P. Rogl, C. Paul, S. Berger, E. Auer, G. Hilscher, C. Godart, H. Noël, A. Saccone, R. Ferro, Physica B 328 (2003) 44-48.

[11] M. Beekman, G. S. Nolas, Physica B 383 (2006) 111-114.

[12] S. Stefanoski, C. D. Malliakas, M. G. Kanatzidis, G. S. Nolas, Inorg. Chem. 51 (2012) $8686-8692$.

[13] J. Gryko, P. F. McMillan, R.F. Marzkc, G. K Ramachandran, D. Patton, S. K. Deb, O. F. Sankey, Phys. Rev B 62 (2000) R7707-R7710.

[14] A. M. Guloy, T. Ramlau, X. Tamg, W. Schnelle, M. Baitinger, Y. Grin, Nature 443 (2006) 320-323.

[15] K. Moriguchi, M. Yonemura, A. Shintani, S. Yamanaka, Phys. Rev. B 61 (2000) 
9859-9862.

[16] R. Himeno, F. Ohashi, T. Kume, E. Asai, T. Ban, T. Suzuki, T. Iida, H. Habuchi, Y. Tutumi, H. Natsuhara, S. Nonomura, J. Non-Cryst. Solids 358 (2012) 2138-2140.

[17] R. Himeno, T. Kume, F. Ohashi, T. Ban, S. Nonomura, J. Alloy Compd. 574 (2013) $398-401$

[18] A. Ammar, C. Cros, M. Pouchard, N. Jaussaud, J. M. Bassat, G. Villeneuve, M. Duttine, M. Ménétrier, E. Reny, Solid State Sci. 6 (2004) 393-400.

[19] T. Ban, T. Ogura, Y. Ohashi, R. Himeno, F. Ohashi, T. Kume, Y. Ohya, H. Natsuhara, T. Iida, H. Habuchi, S. Nonomura, J. Mater. Sci. 48 (2013) 989-996.

[20] L. Miao, S. Tanemura, T. Watanabe, M. Tanemura, S. Toh, K. Kaneko, Y. Sugahara, T. Hirayama, Appl. Surf. Sci. 254 (2007) 167-172.

[21] M. Imai, A. Sato, H. Udono, Y. Imai, and H. Tajima, Dalton T. 20 (2011) 4045-4047.

[22] T. Narita, H. Ueno, T. Baba, T. Kume, T. Ban, T. Iida, H. Habuchi, H. Natsuhara, S. Nonomura, Phys. Status Solidi C 7 (2010) 1200-1202.

[23] S. Stefanoski, M. Beekman, W. Wong-Ng, P. Zavalij, G. S. Nolas, Chem. Mat. 23 (2011) $1491-1495$

[24] J. S. Kasper, P. Hagenmuller, Science 150 (1965) 1713-1714.

[25] H. Horie, T. Kikudome, K. Teramura, S. Yamanaka, J. Solid State Chem. 182 (2009) $129-135$. 
[26] F. Ohashi, M. Hattori, T. Ogura, Y. Koketsu, R. Himeno, T. Kume, T. Ban, T. Iida, H.

Habuchi, H. Natsuhara, S. Nonomura, J. Non-Cryst. Solids 358 (2012) 2134-2137.

[27] von J. Witte, H.G. Schnering, M. von, W. Klemm, Z. Anorg, Allg. Chem. 327 (1964) $260-273$.

[28] M. Tegze, J. Hafner, Phys. Rev. B 40 (1989) 9841-9845.

[29] M. Wilson, P. F. McMillan, Phys. Rev. Let. 90 (2003) 135703.

[30] P. T. Hutchins, O. Leynaud, L. A. O’Dell, M. E. Smith, P. Barnes, P. F. McMillan, Chem. Mat. 23 (2011) 5160-5167. 
Fig.1
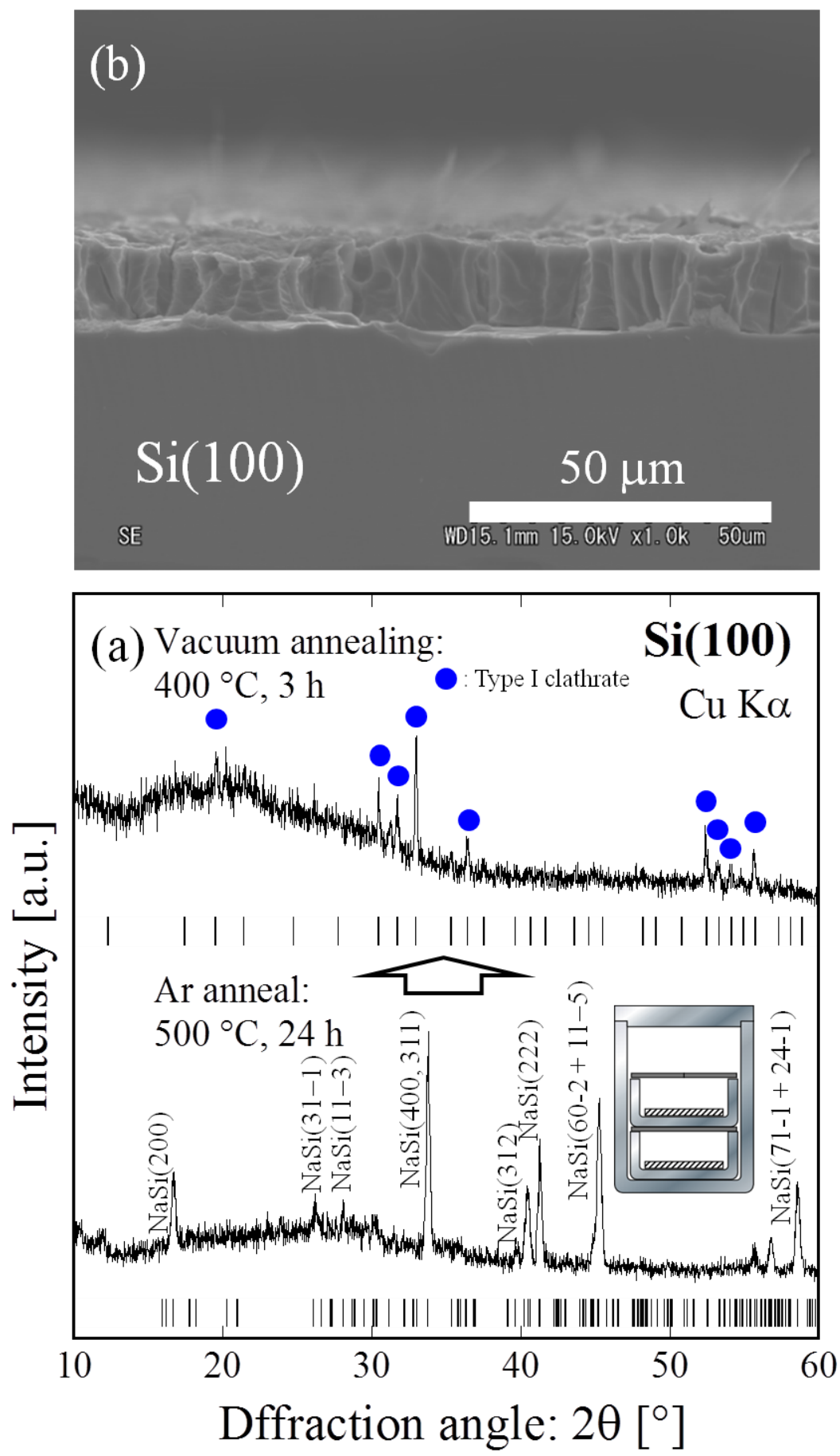

pg. 15 
Fig. 2

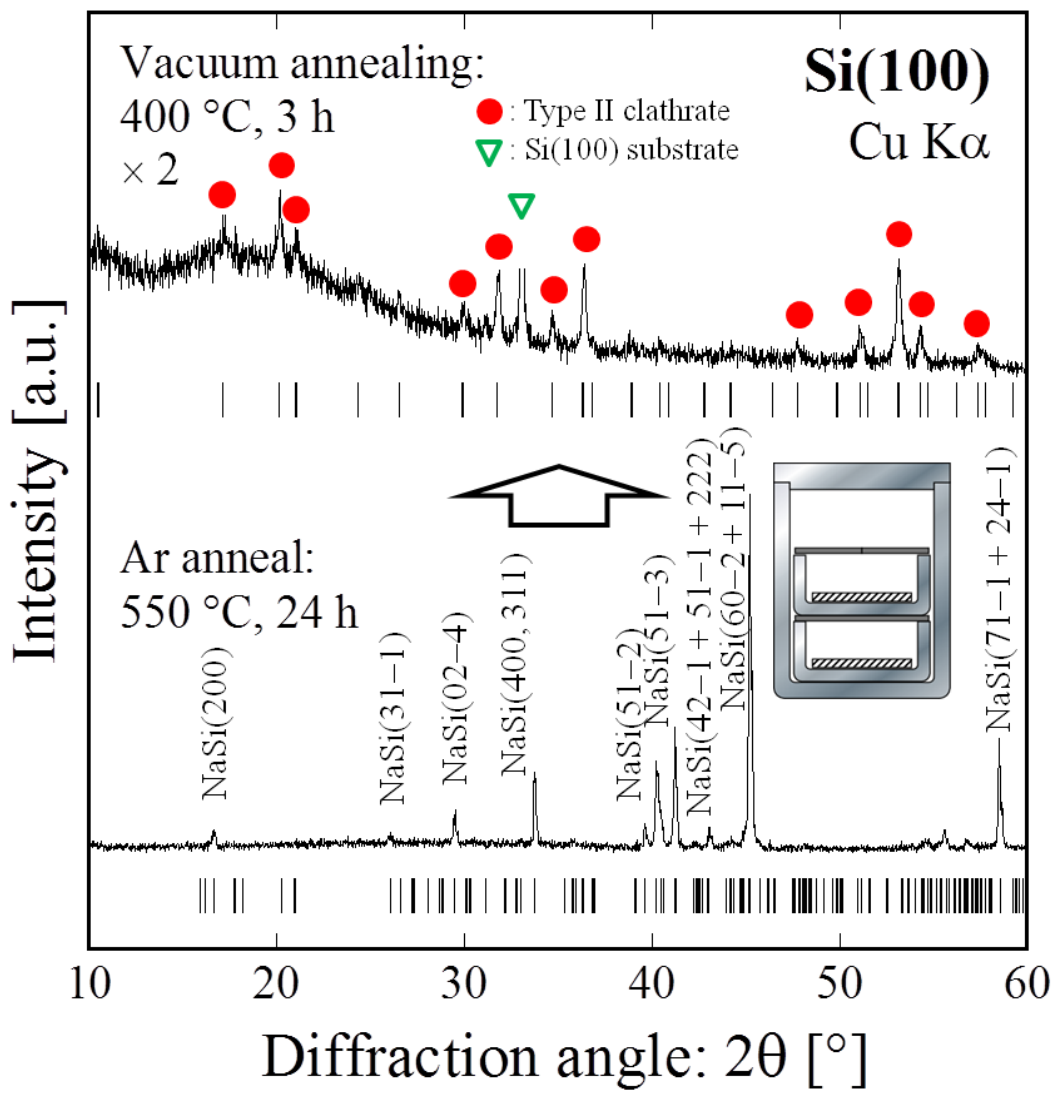

pg. 16 
Fig. 3
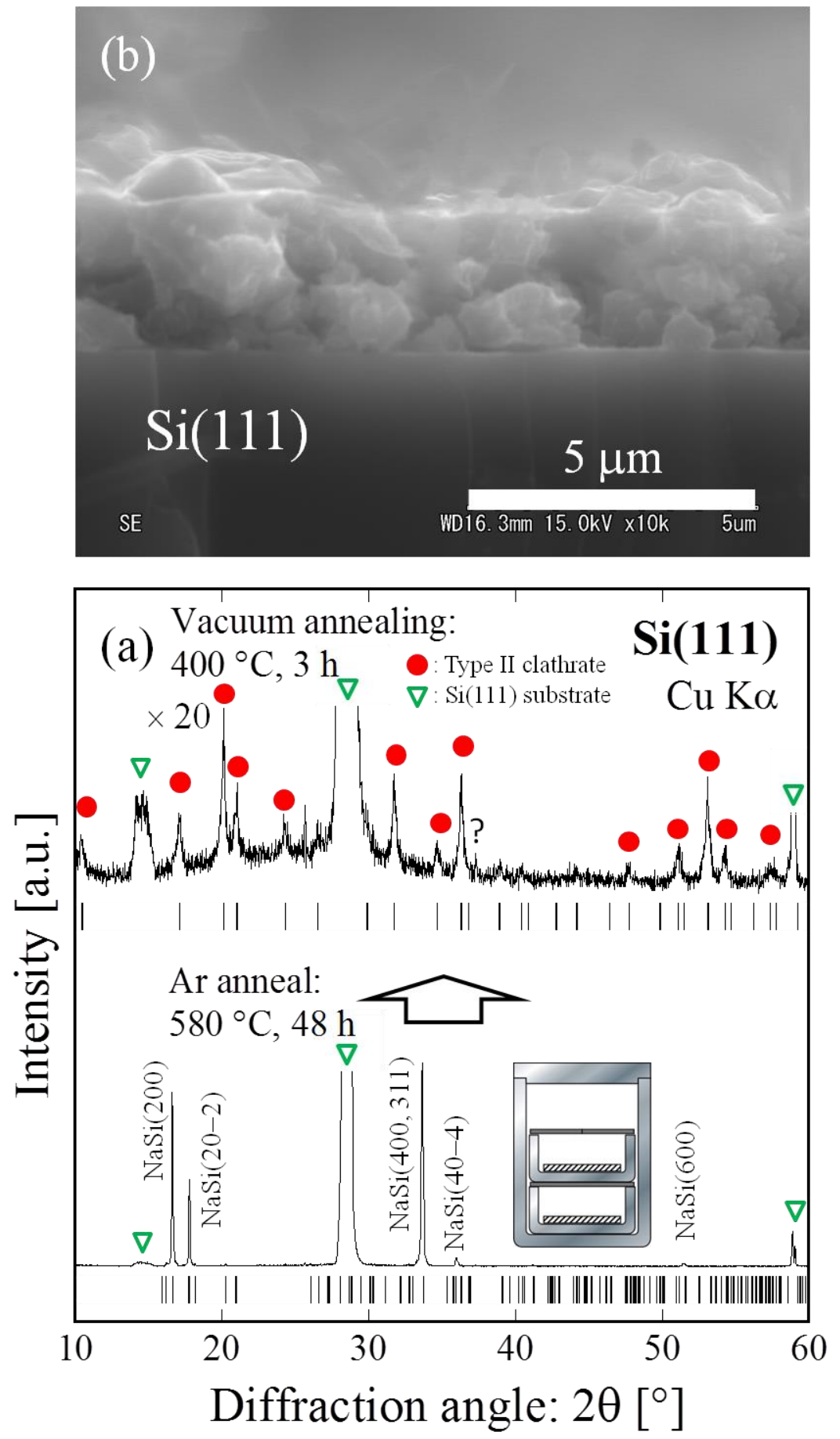

pg. 17 
Fig. 4

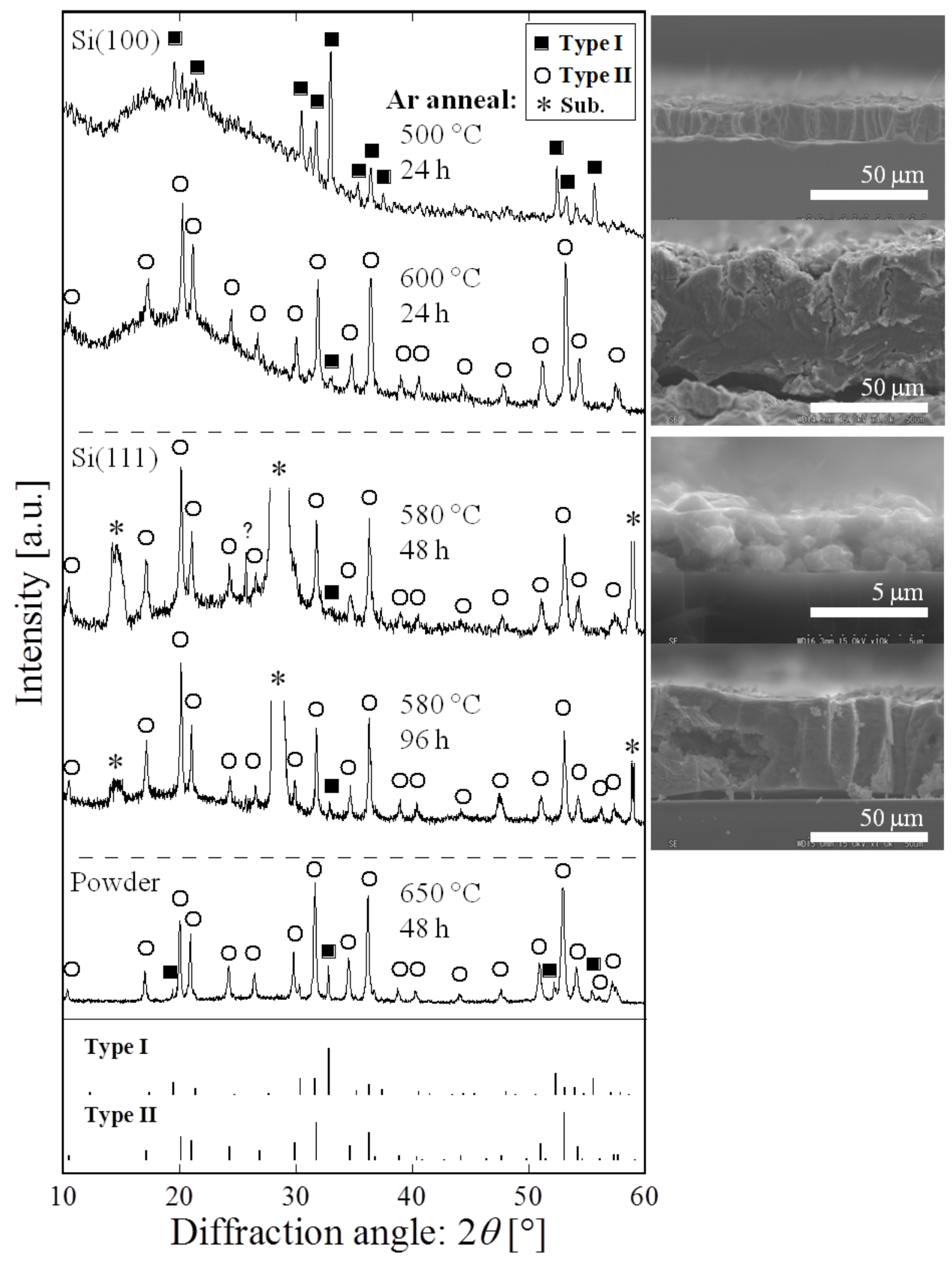

pg. 18 
List of figures

Fig. 1. Characteristics of Si clathrate films and Zintl-phase NaSi films grown on Si(100) substrates. (a) XRD patterns of Si clathrate films (top) and NaSi films (bottom). NaSi and Si clathrate films were prepared under conditions of $500{ }^{\circ} \mathrm{C}$ for $24 \mathrm{~h}$ under an Ar atmosphere and subsequent annealing at $400{ }^{\circ} \mathrm{C}$ for $3 \mathrm{~h}$ under vacuum, respectively. (b) Cross-sectional image of Si clathrate films.

Fig. 2. Characteristics of Si clathrate films and Zintl-phase NaSi films grown on Si(100) substrates. (a) XRD patterns of Si clathrate films (top) and NaSi films (bottom). NaSi and Si clathrate films were prepared under conditions of $550{ }^{\circ} \mathrm{C}$ for $24 \mathrm{~h}$ under an $\mathrm{Ar}$ atmosphere and subsequent annealing at $400{ }^{\circ} \mathrm{C}$ for $3 \mathrm{~h}$ under vacuum, respectively.

Fig. 3. Characteristics of Si clathrate films and Zintl-phase NaSi films grown on Si(111) substrates. (a) XRD patterns of Si clathrate films (top) and NaSi films (bottom). NaSi and Si clathrate films were prepared under conditions of $580{ }^{\circ} \mathrm{C}$ for $48 \mathrm{~h}$ under an $\mathrm{Ar}$ atmosphere and subsequent annealing at $400{ }^{\circ} \mathrm{C}$ for $3 \mathrm{~h}$ under vacuum, respectively. (b) Cross-sectional image of Si clathrate films. 
Fig. 4. XRD patterns and cross-sectional SEM images of Si clathrate films with varying thicknesses on $\mathrm{Si}(100)$ and $\mathrm{Si}(111)$ substrates. Preparation conditions of NaSi films for each Si clathrate film are given at the top of each XRD pattern. Subsequent annealing for the thermal decomposition of NaSi films was conducted at $400{ }^{\circ} \mathrm{C}$ for $3 \mathrm{~h}$ under vacuum for all the samples including the powder sample. The 1st and 3rd XRD patterns and SEM images from the top were the same as those presented in Figs. 1 and 3, respectively. The 1st and 3rd XRD patterns were smoothed to show the diffraction peaks clearly. The 5th XRD pattern was obtained from the powder sample prepared with the Si powder and Na lump. The bar charts at the bottom of the figure show XRD patterns of the type I (JCPDS card 89-5534) and type II (JCPDS card 89-5538) Si clathrates with random crystalline orientation. 